(2) Open Access Full Text Article

\title{
New optical coherence tomography fundus findings in a case of beta-thalassemia
}

\section{Eleftheriadou' \\ PG Theodossiadis' \\ A Rouvas' \\ D Alonistiotis' \\ GP Theodossiadis²}

'2nd Department of Ophthalmology,

"Attikon" University Hospital, University of Athens, ${ }^{2}$ Department of Ophthalmology, "Henry Dunant" Hospital, Athens, Greece
Correspondence: Panagiotis G

Theodossiadis

Ophthalmology Department, University

Hospital Attikon, I Rimini Street, 12462

Chaidari, Athens, Greece

Tel +30 2l 0583 |335

Email patheo@med.uoa.gr
This article was published in the following Dove Press journal:

Clinical Ophthalmology

19 December 2012

Number of times this article has been viewed
Abstract: Patients with beta-thalassemia may present with an acquired diffuse elastic tissue defect due to degeneration of elastic tissue along with vaso-occlusive findings in the retinal microvasculature. Here we report the case of a patient with granular-like accumulation presenting as black sunburst lesions detected by optical coherence tomography (OCT). A 38-year-old man with beta-thalassemia intermedia associated with angioid streaks complained of deterioration of vision in both eyes. Funduscopic examination revealed small, round, hyperpigmented lesions bilaterally. During the early and late phases of fluorescein angiography, granular hyperfluoresence was present, associated with pigment decompensation and mottled-like hypofluorescence. The main OCT finding was the presence of granuloid-like accumulations at the retinal pigment epithelium level. Granule penetration was also noticed at the photoreceptor layer, while isolated granuloid-like accumulations were found in the inner layers of the macula and choroid. In this case, the new OCT finding was the granular-like hyperpigmented accumulations in the macula located at the level of the retinal pigment epithelium. To the best of our knowledge, our OCT findings show for the first time granuloid-like accumulations representing black sunburst lesions.

Keywords: beta-thalassemia, angioid streaks, optical coherence tomography, granuloid-like accumulation, retinal pigment epithelium

\section{Introduction}

Thalassemias are inherited hemoglobinopathies that result in synthesis of abnormal hemoglobin molecules. Beta-thalassemia may cause diffuse pseudoxanthoma elasticum-like elastic tissue defects. The first manifestation of a potential elastic tissue defect described in hemoglobinopathies was angioid streaks in the fundus of the eye, reflecting linear tears of the elastic lamina of Bruch's membrane. ${ }^{1}$ The estimated incidence of angioid streaks in these patients is in the range of $0 \%-6 \%$, and the clinical appearance is strongly age-related..$^{1-4}$ Moreover, fundus findings may be present in patients with beta-thalassemia under hypoxic conditions caused by vasoocclusive events in the retinal microvasculature. We present a case of a patient with beta-thalassemia intermedia associated with angioid streaks, with distinct hyporeflective and hyperreflective macular findings detected by fluorescein angiography and in particular by optical coherence tomography (OCT).

\section{Case report}

A 38-year-old male with beta-thalassemia intermedia was referred to our clinic with impairment of visual acuity in both eyes. The patient did not need blood transfusions or iron chelation therapy. Clinical examination revealed a 
typical thalassemia face without any skin abnormalities. The chest radiograph showed bilateral extramedullary hemopoietic masses as well as an increased cardiothoracic index. X-rays of the lower limbs did not show vascular calcification. Laboratory tests showed $\mathrm{Hb} 7,9 \mathrm{~g} / \mathrm{dL}$, hematocrit $26.9 \%$, red blood cells $3480 / \mu \mathrm{L}$, white blood cells $38,430 / \mu \mathrm{L}$, and erythroblasts $85 \%$. The ophthalmologic examination included color fundus and red-free photographs, fluorescein angiography, OCT, and visual acuity. Visual acuity was 4/10 in the right eye and 5/10 in left eye. The OCT examination was performed using the SOCT Copernicus HR (Optopol, Zawiercie, Poland).

Funduscopic examination revealed multiple, asymmetrical, bilateral bands radiating from the optic disc, corresponding to angioid streaks. The retinal pigment epithelium on either side of the angioid streaks also showed pigment alterations. Small, round, hyperpigmented lesions were also present in the macula of both eyes. Focal retinal pigment epithelium atrophy was also evident.

During both early and late phase fluorescein angiography, granular hyperfluoresence associated with pigment decompensation and mottled-like hypofluorescence were present in the perifoveal and parafoveal areas. Angioid streaks in the early phase were mildly hyperfluorescent, with the stain remaining until the late phase.

The main OCT finding was the presence of granuloid-like accumulations at the retinal pigment epithelium level. Granule penetration was also noticed at the photoreceptor layer while isolated granuloid-like accumulations were found in the inner layers of the macula and the choroid. The retinal pigment epithelium was irregular along its course, with thick and atrophic areas. The inner and outer photoreceptor
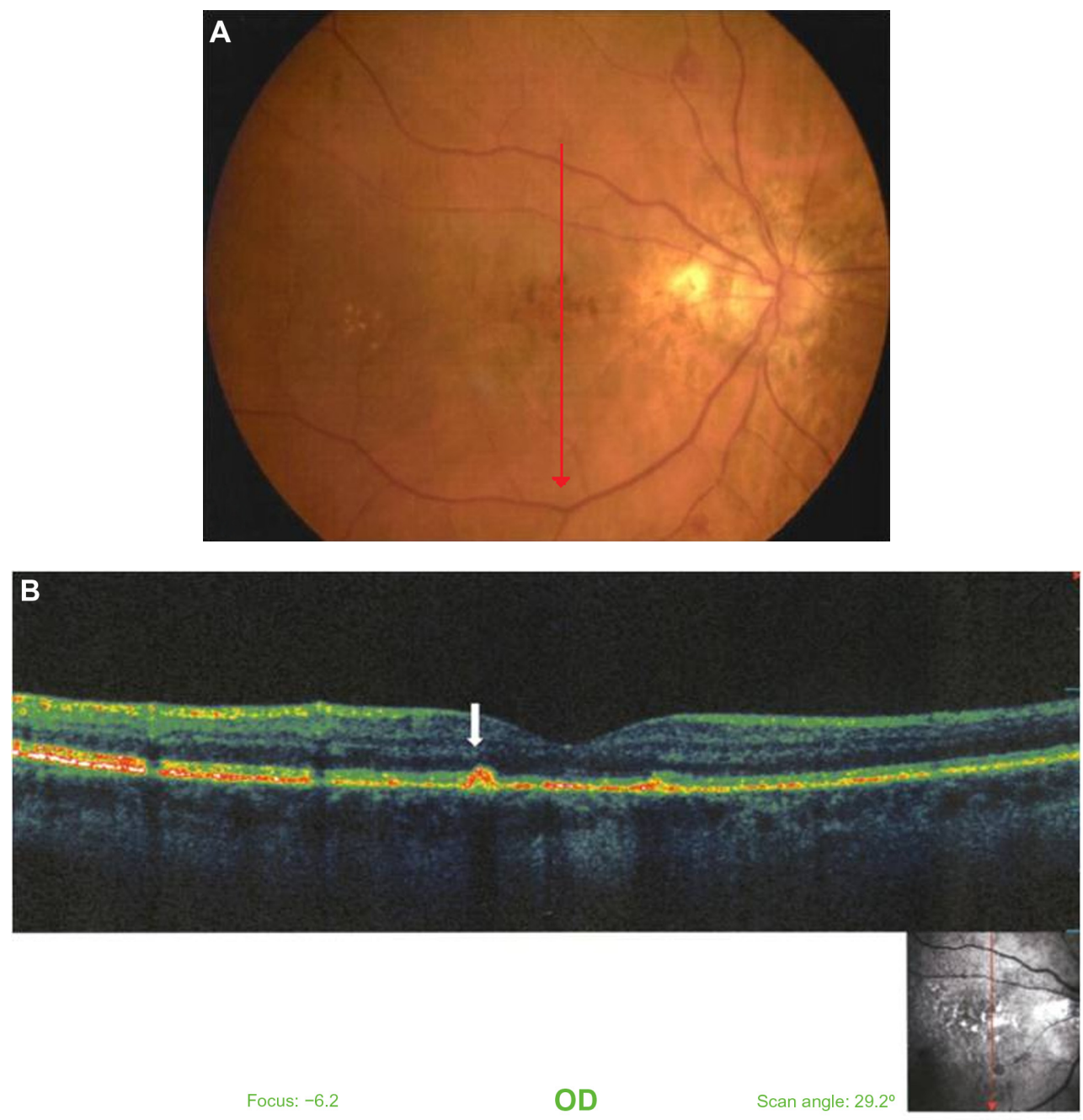

Figure I Color fundus photograph of the right eye in a patient aged 38 years with $\beta$-thalassemia. (A) Fluorescein angiography of the same eye. Hyperpigmented and hypopigmented lesions in the macula are evident. Notice also the presence of angioid streaks. (B) Vertical optical coherence tomography scan through the fovea.

Notes: The thickness of the fovea is $157 \mu \mathrm{m}$. The photoreceptor inner layer/outer layer junction line is not visible. The granuloid-like appearance at the level of pigment epithelium is evident. Notice the irregular thickness of the retinal pigment epithelium and penetration of the granules into the photoreceptor layer in some places (arrow). Abbreviation: OD, right eye. 
layer and the external-limiting membrane were not visible (Figures 1 and 2).

\section{Discussion}

In patients with beta-thalassemia, tissues that are rich in elastic fibers are gradually affected by a degenerative process inducing pseudoxanthoma elasticum-like abnormalities. Angioid streaks, caused by linear crack-like dehiscences in the collagenous and elastic portion of Bruch's membrane, are a common finding in patients with inherited pseudoxanthoma elasticum and may be associated with other funduscopic observations. ${ }^{4,5}$ Widespread diffuse mottling detected as multiple, indistinct, confluent lesions at the level of the retinal pigment epithelium are known as "peau d'orange" changes. These lesions are usually evident in the mid periphery of the fundus, particularly on the temporal side, but in many cases are not stained by fluorescein angiography. ${ }^{6-8}$

Moreover, patients with beta-thalassemia may experience vaso-occlusive events in the retinal microvasculature, where characteristics of red blood cells play a crucial role. The vasoocclusive changes after a sudden arteriolar occlusion and subsequent vessel rupture may result in salmon spot hemorrhages up to one disc diameter in size. As the salmon patch hemorrhage resorbs, small retinoschisis cavities develop, containing yellowish granules that represent multiple hemosiderin-laden macrophages. These lesions have the appearance of glistening spots within the cavity and are known as "iridescent spots". Other findings are round or oval black sunburst lesions, mainly localized in the retinal pigment epithelium. ${ }^{9}$ It is postulated that black sunburst lesions represent the final stage of salmon patch hemorrhage or the result of vascular occlusions in the choroid.
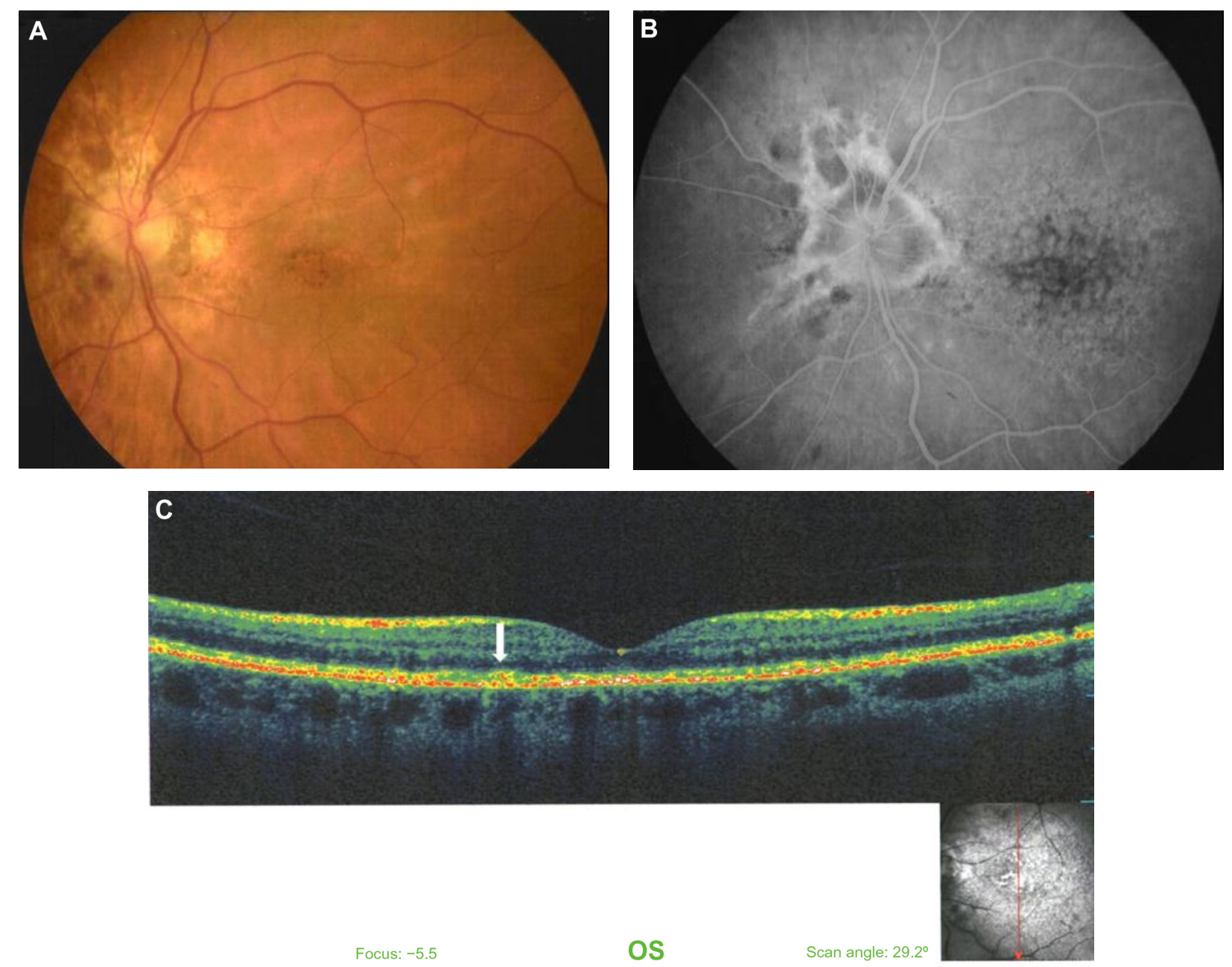

Figure 2 Left eye of the same patient. Color photograph of the fundus of the eye. (A) Early fluorescein angiography phase, depicting the hyperpigmented granuloid-like appearance of the macula. (B) Late fluorescein angiography phase, showing the angioid streaks and the hypopigmented and hyperpigmented lesions of the macula. (C) Vertical optical coherence tomography scan through the fovea.

Notes: Notice the appearance of granuloid-like accumulations at the level of the retinal pigment epithelium and their penetration into the photoreceptor layer (arrow). The photoreceptor inner layer/outer layer junction line is absent. Thickness of the fovea is $152 \mu \mathrm{m}$.

Abbreviation: OS, left eye. 


\section{Conclusion}

In our case, the new OCT finding seems to be the granularlike hyperpigmented accumulations in the macula, located at level of the retinal pigment epithelium. We postulate that these granular-like accumulations in the retinal pigment epithelium and their penetration into some areas in the photoreceptor layer represent black sunburst lesions, probably caused by occlusive vascular changes in the choroicapillaris layer. To our knowledge, this is the first report of an OCT scan depicting granuloid accumulation of black sunburst lesions.

\section{Disclosure}

The authors have no financial support or proprietary interests to declare in relation to this work. Written informed consent was obtained from the patient for publication of this case report and accompanying images.

\section{References}

1. Aessopos A, Farmakis D, Loukopoulos D. Elastic tissue abnormalities resembling pseudoxanthoma elasticum in $\beta$ thalassemia and the sickling syndromes. Blood. 2002;99:30-35.
2. Jensen OA. Bruch's membrane in pseudoxanthoma elasticum. Histochemical, ultrastructural, and x-ray microanalytical study of the membrane and angioid streak areas. Graefes Arch Klin Exp Ophthalmol. 1977;203:311-320.

3. Aessopos A, Savvides P, Stamatelos G, et al. Pseudoxanthoma elasticumlike skin lesions and angioid streaks in beta-thalassemia. Am J Hematol. 1992;41:159-164.

4. Theodossiadis G, Ladas I, Koutsandrea C, Damanakis A, Petroutsos G. Thalassemia and macular subretinal neovascularization. J Fr Ophthalmol. 1984;7:115-118. French.

5. Aessopos A, Floudas SC, Kati M, et al. Loss of vision associated with angioid streaks in $\beta$ thalassemia intermedia. Int J Hematol. 2008;87: 35-38.

6. Zweifel AS, Imamura Y, Freund KB, Spaide RF. Multimodal fundus imaging of pseudoxanthoma elasticum. Retina. 2011;31:482-491.

7. Issa PC, Finger PR, Holz GF, Schol HP. Multimodal imaging including spectral domain OCT and confocal near infrared reflectance for characterization of outer retinal pathology in pseudoxanthoma elasticum. Invest Ophthalmol Vis Sci. 2009;50:5913-5918.

8. Donald J, Gass M. Stereoscopic Atlas of Macular Diseases Diagnosis and Treatment, 3rd ed. Mosby Company; 1987:1.

9. Guyer D, Yannuzzi L, Chang S, Shields J, Green R. Retina-VitreousMacula, 1st ed. Philadelphia, PA: Saunders Company; 1999:1.
Clinical Ophthalmology

\section{Publish your work in this journal}

Clinical Ophthalmology is an international, peer-reviewed journal covering all subspecialties within ophthalmology. Key topics include: Optometry; Visual science; Pharmacology and drug therapy in eye diseases; Basic Sciences; Primary and Secondary eye care; Patient Safety and Quality of Care Improvements. This journal is indexed on

Submit your manuscript here: http://www.dovepress.com/clinical-ophthalmology-journal

\section{Dovepress}

PubMed Central and CAS, and is the official journal of The Society of Clinical Ophthalmology (SCO). The manuscript management system is completely online and includes a very quick and fair peer-review system, which is all easy to use. Visit http://www.dovepress.com/ testimonials.php to read real quotes from published authors. 